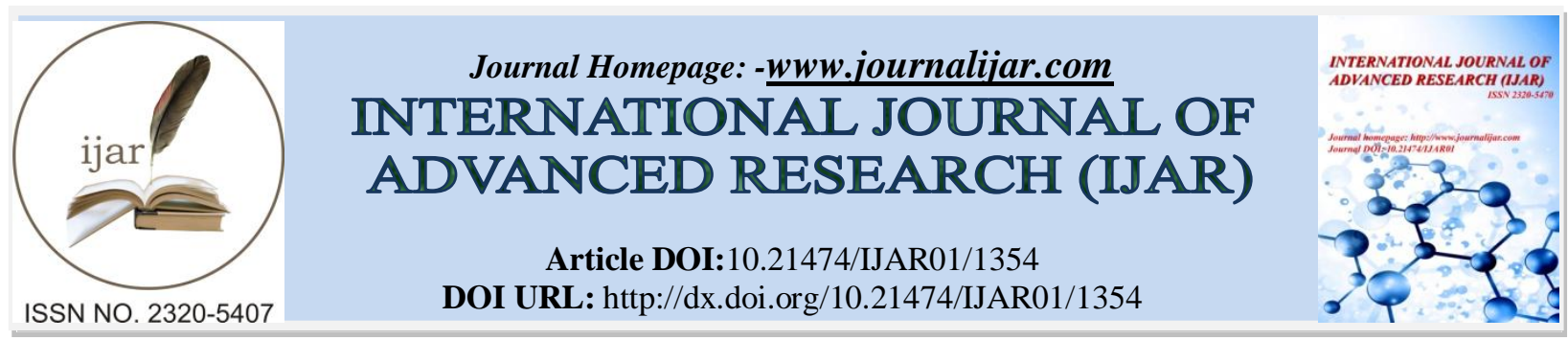

RESEARCH ARTICLE

\title{
ANTIBIOTIC SUSCEPTIBILITY ANALYSIS OF CLINICAL BACTERIAL ISOLATES IN CAIRO, EGYPT.
}

Hussien H. El-Sheikh ${ }^{1}$,SoheirAbdelRahmanSalih ${ }^{2}$, Mahmoud M. Elaasser ${ }^{3}$, Nesreen A. Safwat ${ }^{3}$ and Mostafa $^{1}$ Y. Ibrahim ${ }^{1}$.

1. Department of Botany and Microbiology, Faculty of Science, Al-Azhar University, Cairo, Egypt.

2. Department of Clinical pathology, Faculty of Medicine, Al-Azhar University (Girls Branch), Cairo, Egypt.

3. The Regional Center for Mycology and Biotechnology, Al-Azhar University, Cairo, Egypt

\section{Manuscript Info}

-.........................

Manuscript History

Received: 12 June 2016

Final Accepted: 19 July 2016

Published: August 2016

Key words:-

Multi-drug resistant, antibiotic, bacterial

isolates, urinary tract infection.

\section{Abstract}

In the present report, among one thousand and six hundred urine samples screened; only 65\% showed bacterial infection. However, 919 samples $(88.4 \%)$ were sensitive to the tested antibiotics; 121 samples (11.6\%) recognized as multi-drug resistant bacteria. These bacterial isolates were identified and differentiated by cultural, morphological, and biochemical analysis. The isolates were then analyzed to determine their susceptibility profile to 30 antibiotics according to the standard CLSI guide.The results also indicated that the most of urinary tract infection diseases were by Gram negative bacteria (102 isolates; $84.3 \%$ ). Escherichia coli was the most predominant organism causing UTI in this study that represented by 58 isolates (47.9\%), followed by Klebsiella pneumonia (21.5\%), Pseudomonas aeruginosa (14.9\%), Staphylococcus aureus(12.4\%), Enterococcus faecalis $(3.3 \%)$.In conclusion, the profiles in bacterial clinical isolates can provide important information for the control of antibiotic resistance as well as distribution and susceptibility profiles in populations.

Copy Right, IJAR, 2016,. All rights reserved.

\section{Introduction:-}

Different microorganisms can cause Urinary tract infections including fungi and viruses, but bacteria are the most causative agents and are responsible for 95\% of cases worldwide (Hooton, 2012; Schollum and Walker, 2012).

It has been estimated that more than $60 \%$ of healthcare- associated infections are biofilm-related. Urinary tract infections (UTIs) are the most common type of hospital-acquired infection, accounting for $40 \%$ of all cases and of those $80 \%$ are catheter- associated (Hamill, 2007).

The incidence of urinary tract infections is much higher in adult women due to anatomical and physiological reasons. However due to the urinary tract lesion formation in males and children, it is more dangerous and must be treated immediately to suppress the infection and prevent spreading. A wide spectrum of treatment can be ranging from a single-dose antibiotic treatment of simple cystitis in young females, to rescue nephrectomy for pyonephrosis

Corresponding Author:-Hussien H. El-Sheikh.

Address:-Department of Botany and Microbiology, Faculty of Science, Al-Azhar University, Cairo, Egypt. 
Doctors routinely prescribe powerful antibiotics to treat UTIs, and individuals with recurrent UTI may be prescribed a longer course of treatment. This may lead to the emergence of antibiotic-resistant bacterial strains, which can cause UTIs that are more serious and difficult to treat (Gupta et al., 2011, Sanchez et al., 2012).

UTI poses serious health threat because of antibiotic resistance and high recurrence rate. Bacterial infections caused by antibiotic-resistant isolates have become a major health problem in recent years, since they are very difficult to treat, leading to an increase in morbidity and mortality (Jonaidiet al., 2009).

Inappropriate antimicrobial use due to availability of antimicrobials without prescription or prescribed by nonskilled practitioners can lead to inadequate therapy and contribute to further drug resistance (Yilmazet al., 2009).

Escherichia coli was the most predominant bacterium isolated from urine and responsible to most uncomplicated UTIs (Beyene and Tsegaye, 2011; Demileet al., 2012; Ponnusamy and Nagappan, 2013), followed by Klebsiellaspp., Pseudomonas spp., Proteus spp., Staphylococcus aureus, Enterococcus spp.,Enterobacterspp.andCitrobacterspp. (Theodros, 2010; Abdagireet al., 2014).

In the current study, the susceptibility pattern of pathogenic bacteria isolated from Egyptian UTI patients with special reference to multi-drug resistant bacteria. The development of microbial resistance to the available antibiotics has informed the need to explore natural disease control options.

\section{Materials and Methods:-}

\section{Samples Sources and collection:-}

Clinical specimens were obtained during a period of 24 months (from September 2011 to August 2013). Urine samples were collected from 1600 patient's (males, and females) of different ages from in patients and out patients of two hospitals: Al-Zahraa University Hospital and Cairo Specialized Hospital in Cairo city, Egypt.

Every patient got a sterile dry, wide opening and leak proof container. A "mid-stream" or "clean-catch" urine sample obtained under aseptic precautions in sterile containers. In babies, the urine is collected in sterile self-adhesive plastic bags (Simervilleet al., 2005). Some patients (e.g., elderly people or hospitalized patients) that cannot provide a urine sample in such cases, a catheter was inserted into the bladder to collect urine, this is the best method for providing a contaminant free sample. Specimens were transported in sterile containers and analyzed within one hour of collection (Mahdyet al., 2012).

\section{Laboratory Investigations for Urine Samples:-}

Urine specimens were analyzed by dipstick and microscopy, and then cultured. Test strips (Medi-Test Combi 10 Oxoid $^{\circledR}$, UK) were performed for rapid determination of blood, urobilinogen, bilirubin, protein, nitrite, ketones, ascorbic acid, glucose, $\mathrm{pH}$ value and density in urine. Then wet film of urine deposit is examined for pus, RBCs, casts and crystals. The white blood cells (pus cells) are counted. Also, bacterial count is done within one hour by

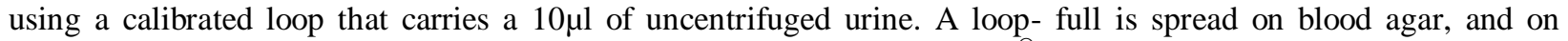
MacConkey or on cystine lactose electrolyte deficient (CLED) agar (Oxoid $\left.{ }^{\circledR}, \mathrm{UK}\right)$ and incubated overnight at $37^{\circ} \mathrm{C}$. The number of bacteria is estimated and interpreted as follows:

$>1 \times 10^{5}$ bacteria per $\mathrm{ml}$ or more indicates urinary tract infections.

$>$ Less than $1 \times 10^{4}$ bacteria per $\mathrm{ml}$ are regarded as contamination.

$>$ A count of $1 \times 10^{4}$ is considered significant if the organism is Gram positive and of one type only.

\section{Isolation and Purification of Uropathogenic Bacteria:-}

Patient's specimens were taken from urinary tract infection cultured by the "Plating out" technique, on solid media. The media used for isolation of bacteria (aerobic as well as facultative anaerobic bacteria) from urine samples under investigation were nutrient agar medium, MacConkey agar medium, Blood agar medium, Chocolate agar medium and Cysteine-Lactose-Electrolyte-Deficient (CLED) medium purchased from Oxoid, UK. All plates were incubated aerobically at $37^{\circ} \mathrm{C}$ for 24 hours. The colonies were picked up by sterile loop and subjected to purification in the same isolation medium. Agar streak method was used for purification process. A well separated colony from each isolate was picked up on isolation medium, slants and incubated at $37^{\circ} \mathrm{C}$ for $24 \mathrm{hrs}$. The purified isolates were subjected to a complete identification process and other studies. 


\section{Methods of Identification of Bacterial Isolates:- Morphological Studies:}

The morphological characteristics of the purified bacterial isolates were carried out according to the identification charts (Holt et al., 1996).

Examination of unstained preparations (wet mount) will help in demonstrating motility. While examination of Gram stained preparation- will determine the staining reaction of the organism; whether Gram-positive or Gram-negative, their morphology (cocci, bacilli, etc.), size and arrangement (Chessbrough, 2000).

\section{Physiological and Biochemical Identification:-}

Many biochemical reactions were preceded for identification of bacteria according to the keys of Bergey's manual of determinative bacteriology (Hensyl, 1994).

\section{Identification of The Bacterial Isolates by Analytical Profile Index (API) strips:-}

The identification of all bacterial isolates was performed using API strips inoculated and incubated as described by the manufacturer (bio Merieux ${ }^{\circledR}$ France). The strips were API 10S, API 10 Strep and API 20 staph. Examination of the strips was conducted after $18-24 \mathrm{hr}$. incubation at $37^{\circ} \mathrm{C}$. The analyses were done using API instrument (bio Merieux ${ }^{\circledR}$ Vitek Systems).

\section{Antibiotic Sensitivity Tests:-}

Antibiotic sensitivity of uropathogen isolates were preformedin-vitro by modified Kirby-Bauer disk diffusion method using Mueller-Hinton agar medium $\left(\mathrm{Oxoid}^{\circledR}\right.$, UK), according to the recommended method of Clinical Laboratory Standards Institute (CLSI, 2012). The Mueller-Hinton Agar plates were inoculated with the bacterial suspension within 15 minutes after adjusting the turbidity of the inoculum suspension, by dipping a sterile cotton swab into the suspension. The swab was then streaked over the entire surface of the Mueller-Hinton medium three times, rotating the plate approximately 60 degrees after each application to ensure an even distribution of the inoculum. The disc diffusion method was applied using commercial paper discs impregnated with antibiotics (Oxoid ${ }^{\circledR}$, UK). 30 different antibiotic discs were applied to the plates within 15 minutes after inoculation. By using a multidisc dispenser, the appropriate discs were placed on the surface of the inoculated plate suitably spaced ( $25 \mathrm{~mm}$ from disc to disc and $15 \mathrm{~mm}$ from the rim). The plates were allowed to pre-diffuse at $4^{\circ} \mathrm{C}$ for one hour. Plates were incubated at $37^{\circ} \mathrm{C}$ for $24 \mathrm{~h}$., and then measured the inhibition zones diameter in millimeter $(\mathrm{mm})$ including the disc $(6 \mathrm{~mm})$. According to the diameter of the inhibition zone, as documented from standard antimicrobial sensitivity charts for the different antibiotics, it can be determined if the organism is sensitive, intermediate or resistant to the different antibiotics according to Clinical Laboratory Standard Institutes guidelines (CLSI, 2012).

\section{Results and Discussion:-}

As the result of increasing mis-use and extensive uses of antimicrobial agents, nosocomial pathogens have shifted away from easily treatable bacteria towards more resistant bacteria. This change is important problem for nosocomial infection control and prevention (Jain et al; 2007).

In this study during 2011 to 2013, urine samples were collected in Al-Zahraa University Hospital and Cairo Specialized Hospital in Cairo city from 1600 patient's males and females of different ages. The results showed that among the 1600 urine samples collected from patients 1040 samples exhibited bacterial growth (65\%) and 560 samples (35\%) did not showed any bacterial growth under these screening conditions (Fig.1). Among the 1040 bacterial-infected patients, only 121 samples (11.6\%) recognized as multi-drug resistant bacteria. However, 919 samples $(88.4 \%)$ were sensitive to the tested antibiotics.Among the ward samples collected; the frequency of multidrug resistant patient are higher $(75.2 \%)$ in In-patient samples $(n=91)$. Moreover, the out-patient samples $(n=30)$ represent only $24.8 \%$ (Fig. 2). From the screening results, it was found that the adult females are the most patients infected by urinary tract infections $(n=69,57.0 \%)$, followed by adult males $(n=31,25.6 \%)$, then child females infected $(n=13,10.8 \%)$ more than child males $(n=8,6.6 \%)$ as shown in fig. (3).For adult females infected with urinary tract infection, the percentage of non-pregnant women about $(95.7 \%, \mathrm{n}=66)$ and the remaining were pregnant women (4.3\%, $\mathrm{n}=3$ ) (Fig. 4). Regarding to sample type, the majority of samples infected with bacteria were fresh mid-stream urine $(n=115,95.04 \%)$, while the urine samples from urinary catheter $(n=6)$ representing $4.96 \%$ (Fig. 5). 
Similarly, McLoughlin and Matar (2003) isolated 126 urine cultures; the majority of organisms were Escherichia coli accounting for $89 \%$ of the patients. Similarly, It has been reported that Escherichia coli was the most frequently occurring pathogen (54.8\%), followed by Klebsiella pneumonia (16.0\%), Staphylococci (11.2\%), Enterobacterspp. (9.6\%), Proteus spp. 1.4\% and Pseudomonas aeruginosa(1.4\%) (Kalantaret al., 2008).

However, all bacterial isolates were screened concerning their sensitivity to different antibiotics on Mueller Hinton agar mediumby disc agar diffusion method.The total pattern of resistance according to each antibiotic of the different 30 antibiotics used is represented for selection of antibiotic resistant bacteria, 121 bacterial isolates were called multi resistant bacteria after compare the inhibition zone around each antibiotic disc with inhibition zone standard according to (NCCLS, 2014).

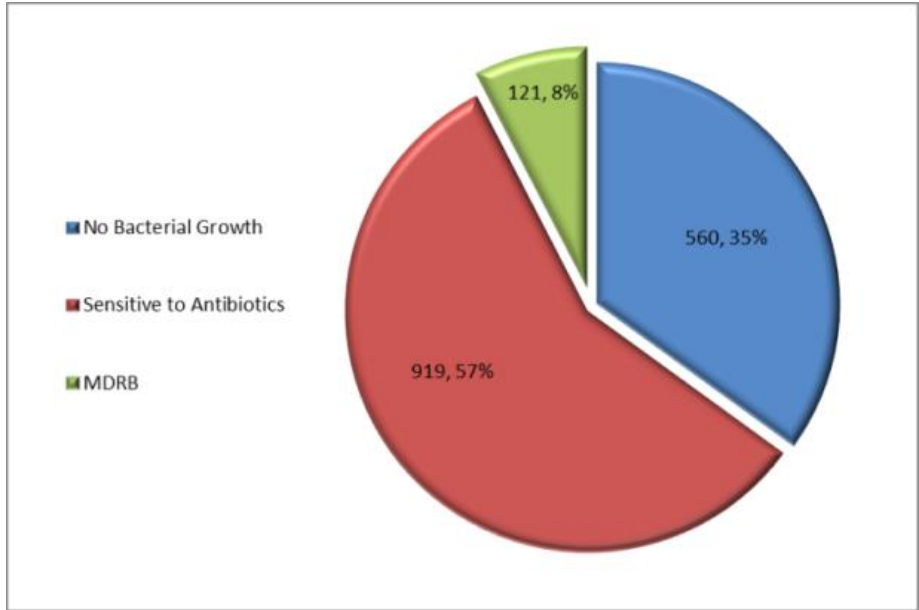

Fig. 1:- The percentages of 1600 urine samples in response to antibiotics.

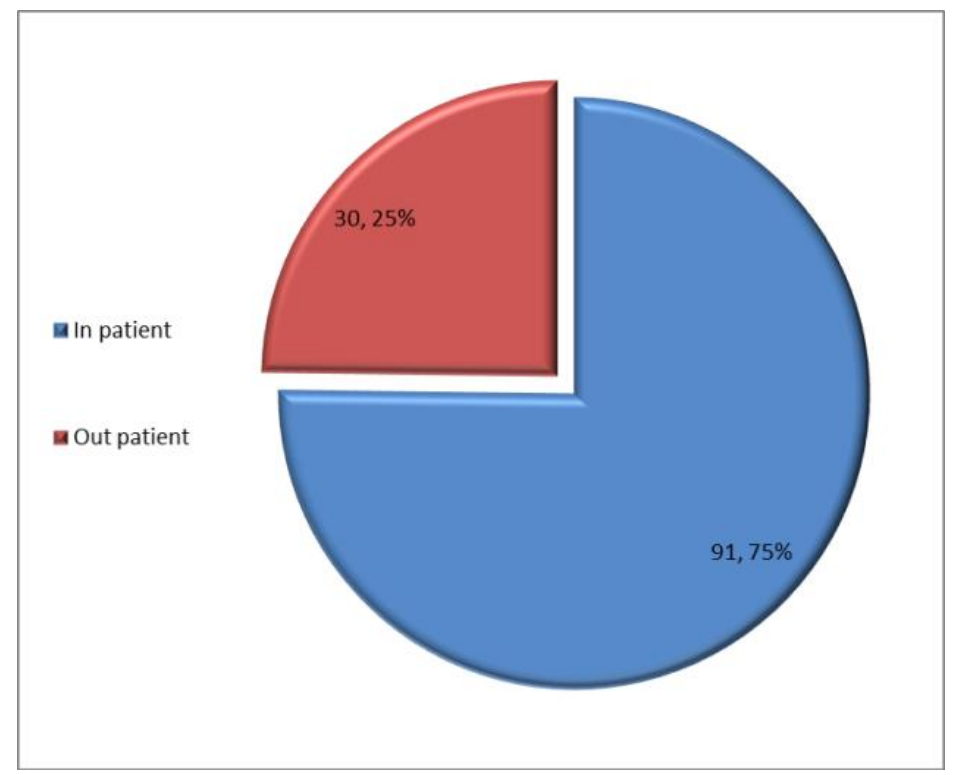

Fig.2:- Percentage of bacterial specimens in relation to hospital (in or out patients). 


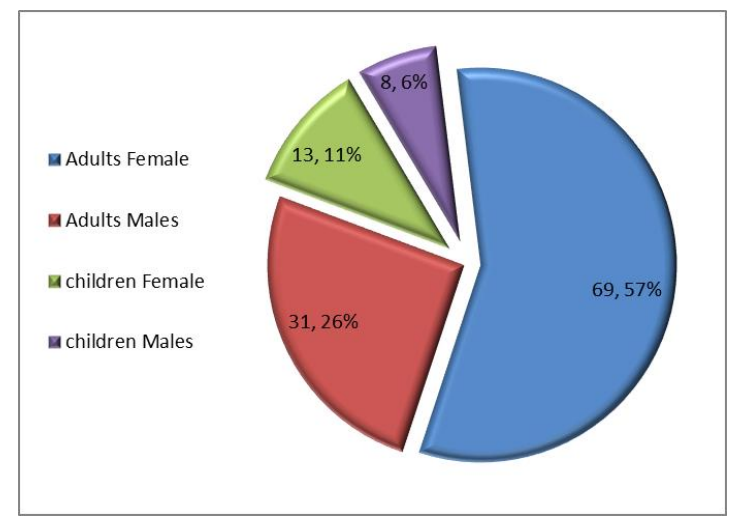

Fig.3:-The percentage of multidrug resistant samples regarding the sex and age stage of patients.

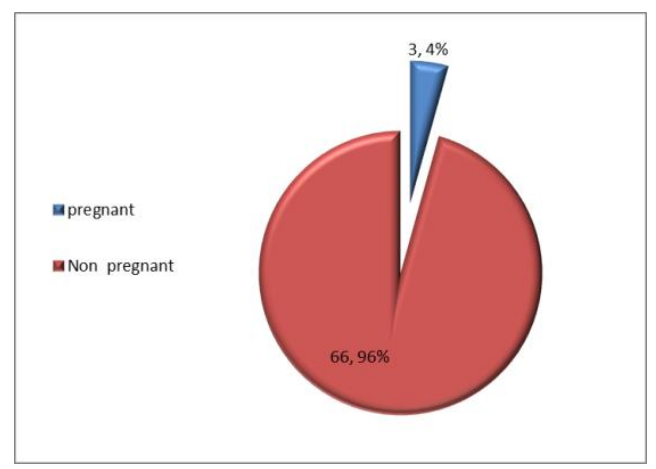

Fig 4:- The percentage of multidrug resistant samples regardingpregnancy in adult females patients.

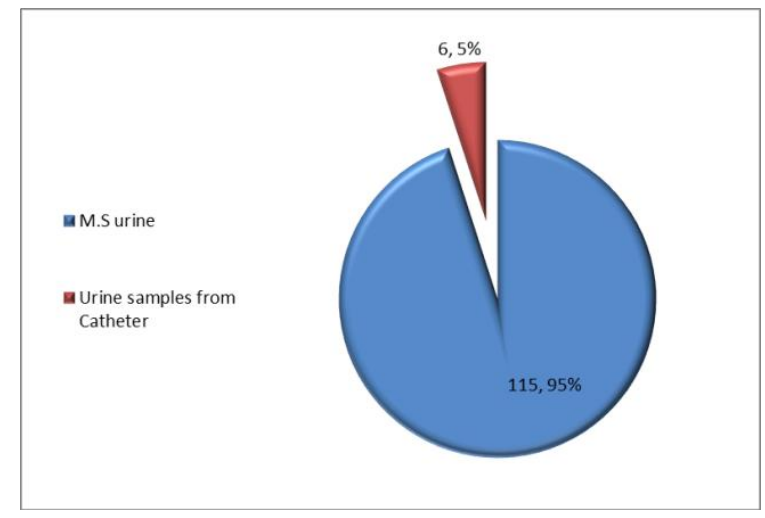

Fig.5:- The distribution of multidrug resistant samples regardingthe sample types.

Uropathogen isolates which are resistant to antibiotics are collected in fig.(6). The tested 121 bacterial isolates did not exhibit sensitivity to the antibiotics Ampicillin (AMP), Ampicillin/Sulbactam (SAM),Aztreonam (ATM), Erythromycin (E),Piperacillin (PRL) and Tobramycin (TOB) under these screening conditions. Moreover, these antibiotics showed low number of intermediate susceptibility expressed as 2, 16, 28, 8, 8 and 9 samples against AMP, SAM, ATM, E, PRL and TOB, respectively. However, more than $75 \%$ of the cases were resistant.

The results revealed that less than $5 \%$ of the uropathogen isolates were sensitive to Cefepime (FEP),Cefoperazone (CFP), Cefotaxime (CTX), Ceftazidime (CAZ), Ceftariaxone (CRO), Cefuroxime (CXM), Doxycycline (DO),Ertapenem (ETP), Nalidixic Acid (NA), Norfloxacin (NOR), Ofloxacin (OFX), Tetracycline (TE), Trimethoprim/Sulfamethoxazole (SXT). While the resistant to these antibiotics was approaching up to $95 \% ; 49.6 \%$, $72.7 \%, 71.0 \%, 69.4 \%, 63.6 \%, 77.7 \%, 94.2 \%, 84.3 \%, 94.2 \%, 52.1 \%, 45.5 \%, 73.5 \%, 68.6 \%$ respectively. Regarding 
to intermediate to previous antibiotics: $46.3 \%, 26.5 \%, 26.5 \%, 28.9 \%, 33.9 \%, 21.5 \%, 5 \%, 12.4 \%, 5 \%, 44.6 \%$, $51.2 \%, 24.8 \%$, and $27.3 \%$, respectively.

In case of Amikacin (AK) $43 \%$ bacterial isolates were sensitive; 36.4\% bacterial isolates were intermediate and $20.6 \%$ bacterial isolates were resistant. However, the susceptibility ofAmoxycillin/Clavulanic Acid (AMC) revealed $2.5 \%$ sensitive, $21.5 \%$ intermediate and $76 \%$ resistant.

It was obvious from the results that $38.8 \%$ were resistant to Ciprofloxacin (CIP), $52.1 \%$ were resistant to Gentamicin $(\mathrm{CN}), 43.8 \%$ were resistant to Levofloxacin (LEV), $46.3 \%$ were resistant to Nitrofurantion (F), $43.0 \%$ were resistant to Piperacillin/Tazobactam (TZP), 50.4\% were resistant to Tigecycline (TGC). However, clinical isolates were intermediate to antibiotics; $54.6 \%, 42.1 \%, 28.1 \%, 37.2 \%, 31.4 \%, 34.7 \%$, respectively. On the other hand, clinical bacterial isolates were sensitive to previous antibiotics; $6.6 \%, 5.8 \%, 28.1 \%, 16.5 \%, 25.6 \%, 14.9 \%$, respectively.

In case of Meropenem (MEM) 21.5\% bacterial isolates were resistant against this particular antibiotic and the same percentage isolates showed intermediate, while 57\% showed sensitivity toward. However, in case of Polymyxin B (PB) $71.1 \%$ bacterial isolates were sensitive, but $18.2 \%$ showed intermediate, while $10.7 \%$ showed resistant toward this particular antibiotic.

The most efficient antibiotic used in this study was Imipenem (IPM); hence $89.3 \%$ of tested clinical bacterial isolates were sensitive to this antibiotic; $6.6 \%$ were intermediate and $4.1 \%$ were resistant.

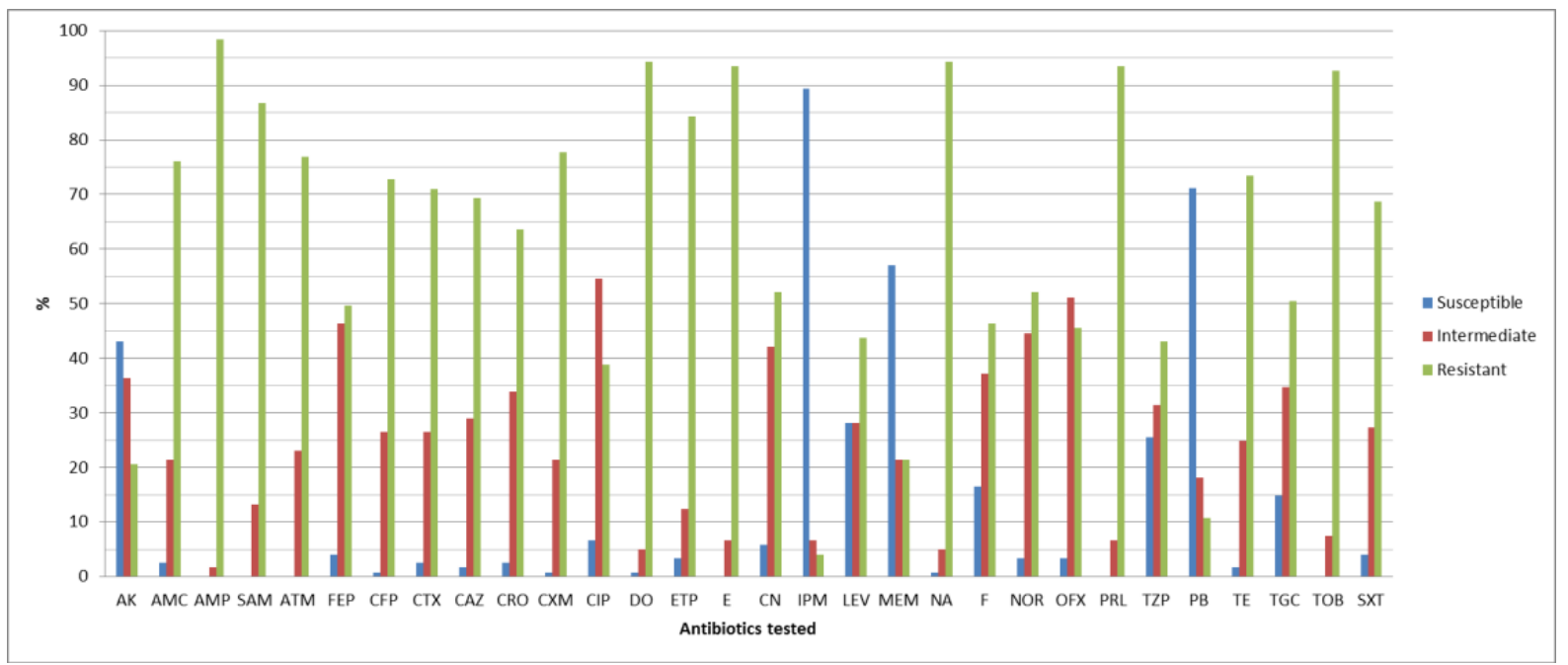

Fig.6:- The percentage of susceptibility of the multi-drug resistant bacterial isolates to the tested antibiotics.

Identification of isolated bacteria was preceded by using consumption of both manual some biochemical tests and Analytical profile Index (API) system. The number and percentage of the etiological agents of UTI were recorded in fig. (7) indicated that there are five different organisms of uropathogen bacteria. Escherichia coli was the most predominant organism causing UTI represented by 58 isolates ( $47.9 \%$ ), followed by Klebsiella pneumonia (26 isolates; $21.5 \%$ ), Pseudomonas aeruginosa(18 isolates; $14.9 \%$ ), Staphylococcus aureus (15 isolates; $12.4 \%$ ), Enterococcus faecalis (4 isolates; $3.3 \%$ ). That's means that the most of urinary tract infection diseases were by Gram negative bacteria (102 isolates; $84.3 \%$ ). While in case of Gram positive low isolates number (19 isolates) with percentage $15.7 \%$. 


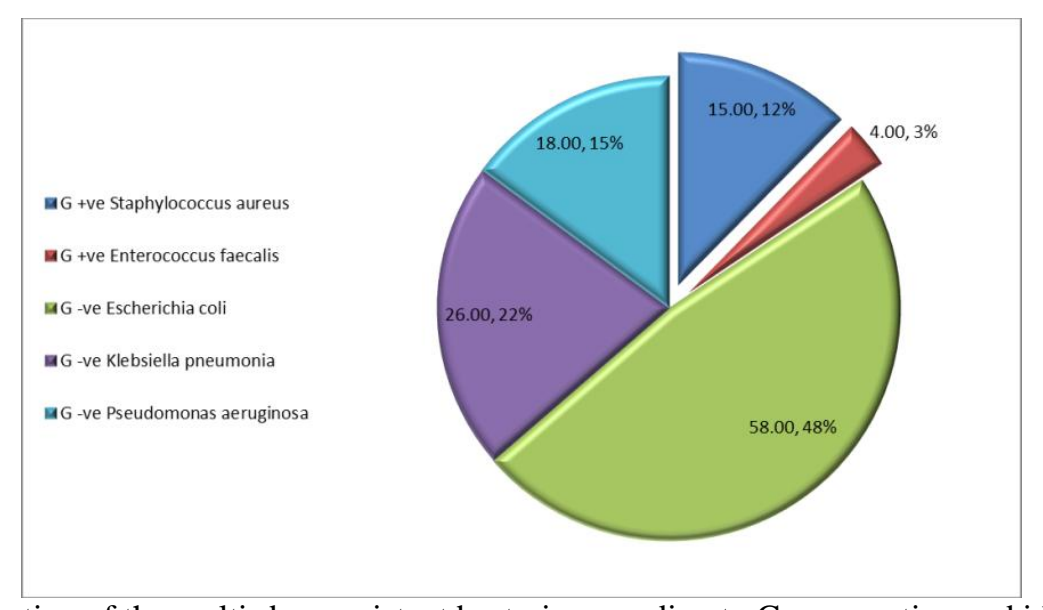

Fig.7:- Distribution of the multi-drug resistant bacteria according to Gram reaction and identification.

Fifty eight antibiotic resistant Escherichia coli isolates were identified from 121 multi-drug resistant isolated from urinary tract infection with percentage $47.9 \%$ and showed antibiotic sensitivity percentage $6.7-20 \%$, intermediately percentage 10.0-46.7\%, resistance percentage 40-76.7\%.Isolate code 370812 was extreme multi-drug resistant Escherichia coli isolate was resistant to AMP, SAM, CAZ, CIP, DO, ETP, E, CN, LEV, NA, NOR, OFX, PB, TE, TGC, TOB, SXT. Also, isolate 370812 showed sensitivity only to IPM and MEM antibiotics; while showed intermediate reaction to AK, AMC, ATM, CEP, CFP, CTX, CRO, CXM, F, TZP (Fig. 8; Table 1).

Within 121 multi-drug resistant isolates were identified twenty six isolates as Klebsiella pneumonia with percentage $21.5 \%$, showing antibiotic sensitivity percentage $6.7-16.7 \%$, intermediately percentage $6.7-50.0 \%$, resistance percentage 36.7-83.3\%.Isolate code 410713 was extreme multi-drug resistant Klebsiella pneumonia isolate was resistant to AMC, AMP, ATM, CAZ, CXM, DO, ETP, E, LEV, NA, NOR, OFX, PRL, TOB. This isolate was sensitive to IPM and MEM antibiotics only. While showed intermediately to AK, SAM, ATM, FEP, CFP, CTX, CTP, CN, F, PB, TE, TGC, SXT (Fig. 9; Table 1).

However, Pseudomonas aeruginosaisolates accounted for 14.9\% (18) from 121 multi-drug resistant bacteria recording antibiotic sensitivity percentage $6.7-16.7 \%$, intermediately percentage $13.3-30.0 \%$, resistance percentage 56.6-73.3\%.Isolate code 270712 was extreme multi-drug resistant Pseudomonas aeruginosa isolate that was resistant to AMC, AMP, SAM, ATM, CFP, CTX, CAZ, CXM, DO, ETP, E, LEV, NA, NOR, OFX, PRL, TZP, TE, TGC, TOB, SXT. While showed intermediately to AK, FEP, CRO, CIP, CN, MEM, F. This isolate was sensitive to IPM and PB antibiotics only (Fig. 10; Table 1).

On the other hand, fifteen antibiotic resistant isolates (12.4\%) were identified as Staphylococcus aureus from 121 multi-drug resistant isolated from urinary tract infection and showed antibiotic sensitivity percentage 10-16.7\%, intermediately percentage $13.3-36.7 \%$, as well as higher resistance percentage 46.7-76.7\%.Isolate Staphylococcus aureus-code 100213- showed extremely multi-drug resistant. Isolate was resistant to AMC, AMP, SAM, ATM, FEP, CTX, CAZ, CRO, CXM, CIP, DO, CN, E, LEV, MEM, NOR, OFX, PRL, TZP, TGC, TOB, SXT. While showed intermediate reaction to CFP, NA, F, TE. This isolate was showed sensitivity against AK, IPM and MEM antibiotics (Fig. 11; Table 1).

Enterococcus faecalisisolates accounted for 3.3\% $(\mathrm{n}=4)$ from 121 multi-drug resistant bacteria which isolated from urinary tract infection that showed antibiotic sensitivity percentage $6.7-13.3 \%$, intermediately percentage $6.7-36.7 \%$, as well as resistance percentage 53.3-86.7\%.Isolate code 270412 was extreme multi-drug resistant Enterococcus faecalisthat was resistant to AK, AMC, AMP, SAM, ATM, FEP, CFP, CTX, CAZ, CRO, CXM, CIP, ETP, E, CN, IPM, LEV, MEM, NA, NOR, OFX, PRL, TZP, TGC, SXT. This isolate was sensitive to DO, TE antibiotics only and intermediately to PB, TOB (Fig. 12; Table 1). 


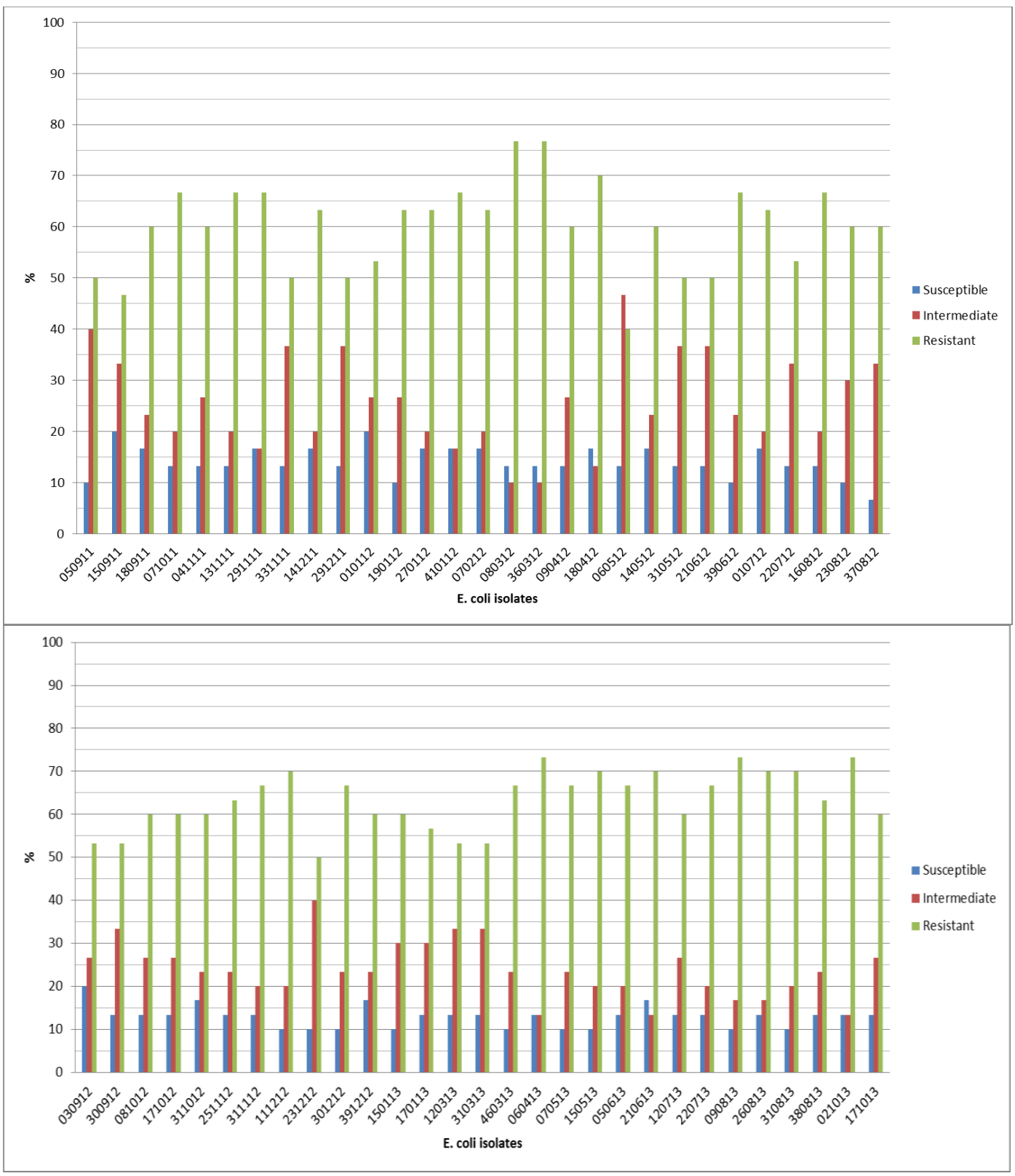

Fig. 8:- The variation in the susceptibility of the multi-drug resistant $E$. coli isolates to the tested antibiotics. 


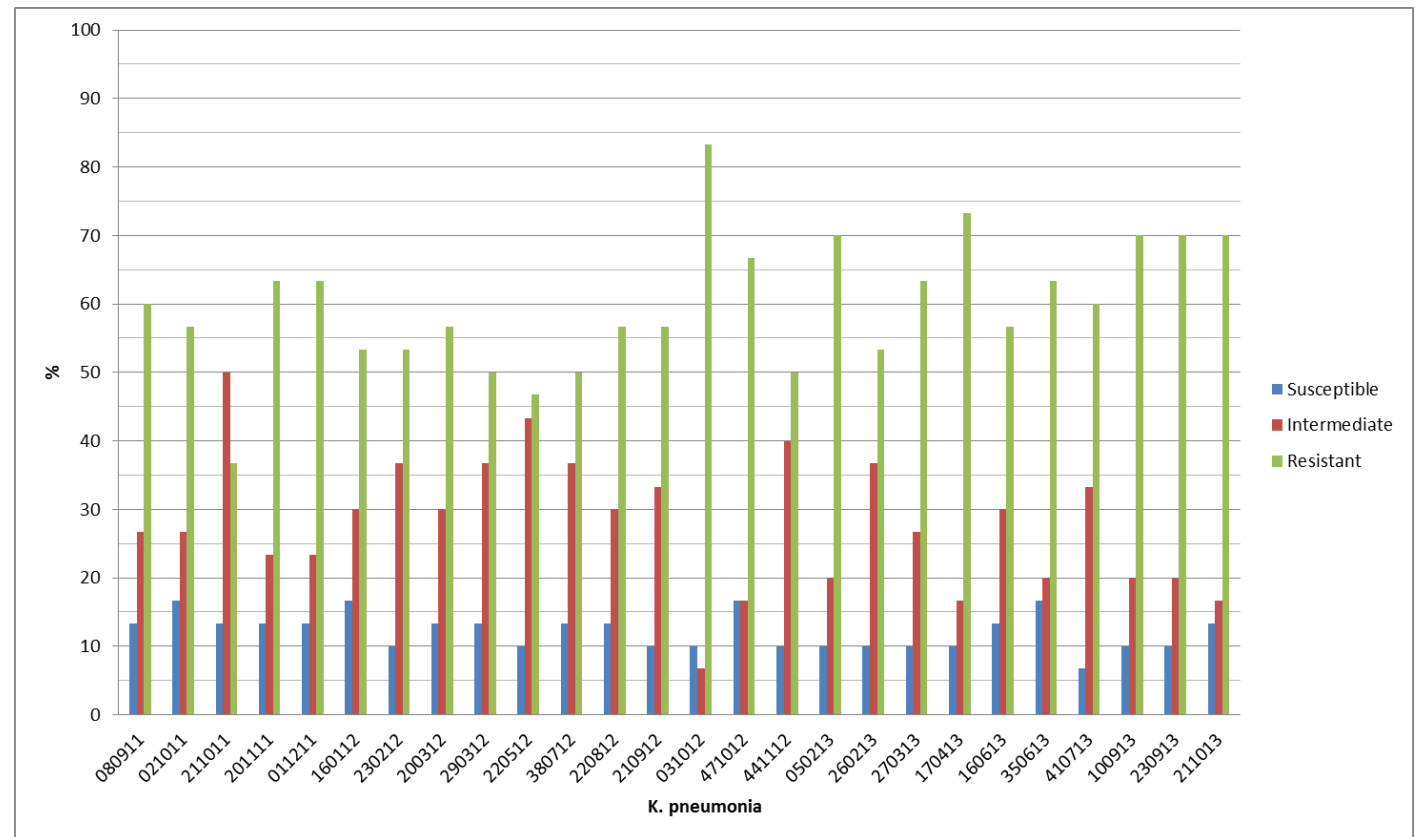

Fig. 9:- The variation in the susceptibility of the multi-drug resistant Klebsiella pneumoniaisolates to the tested antibiotics.

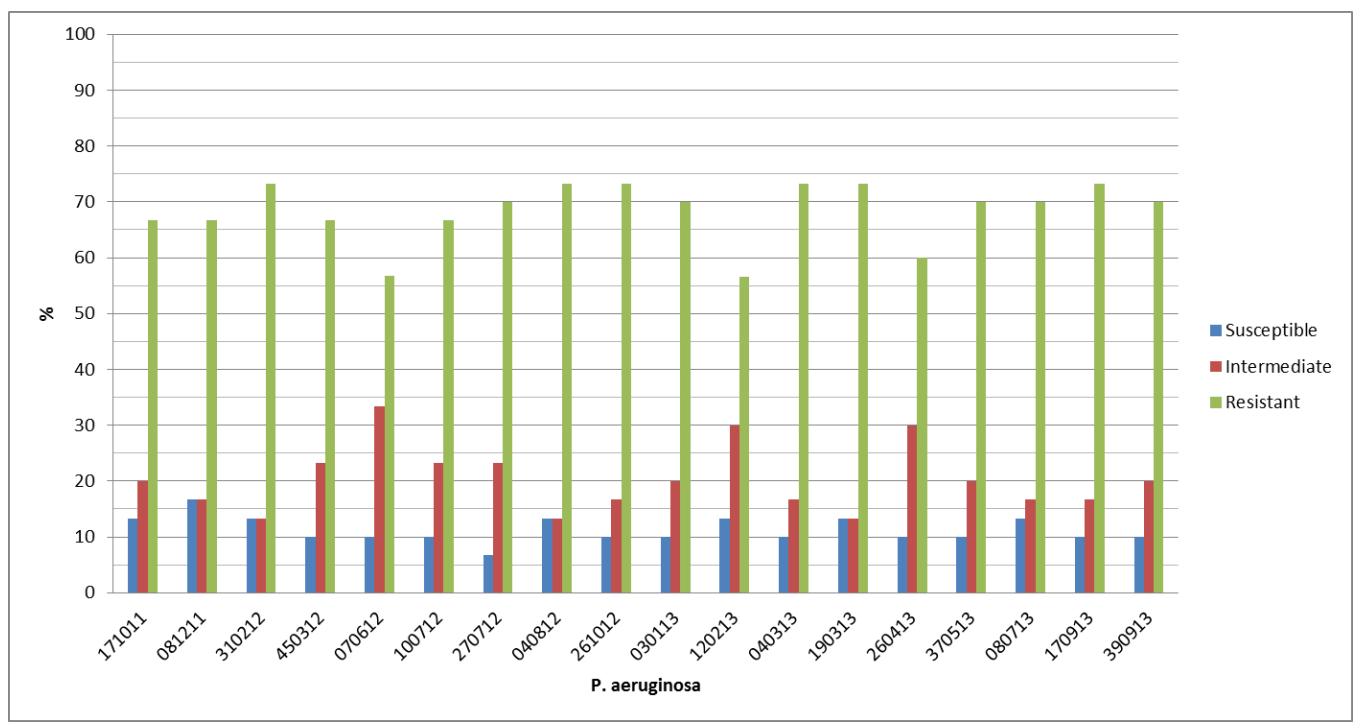

Fig.10:- The variation in the susceptibility of the multi-drug resistant Pseudomonas aeruginosa isolates to the tested antibiotics. 


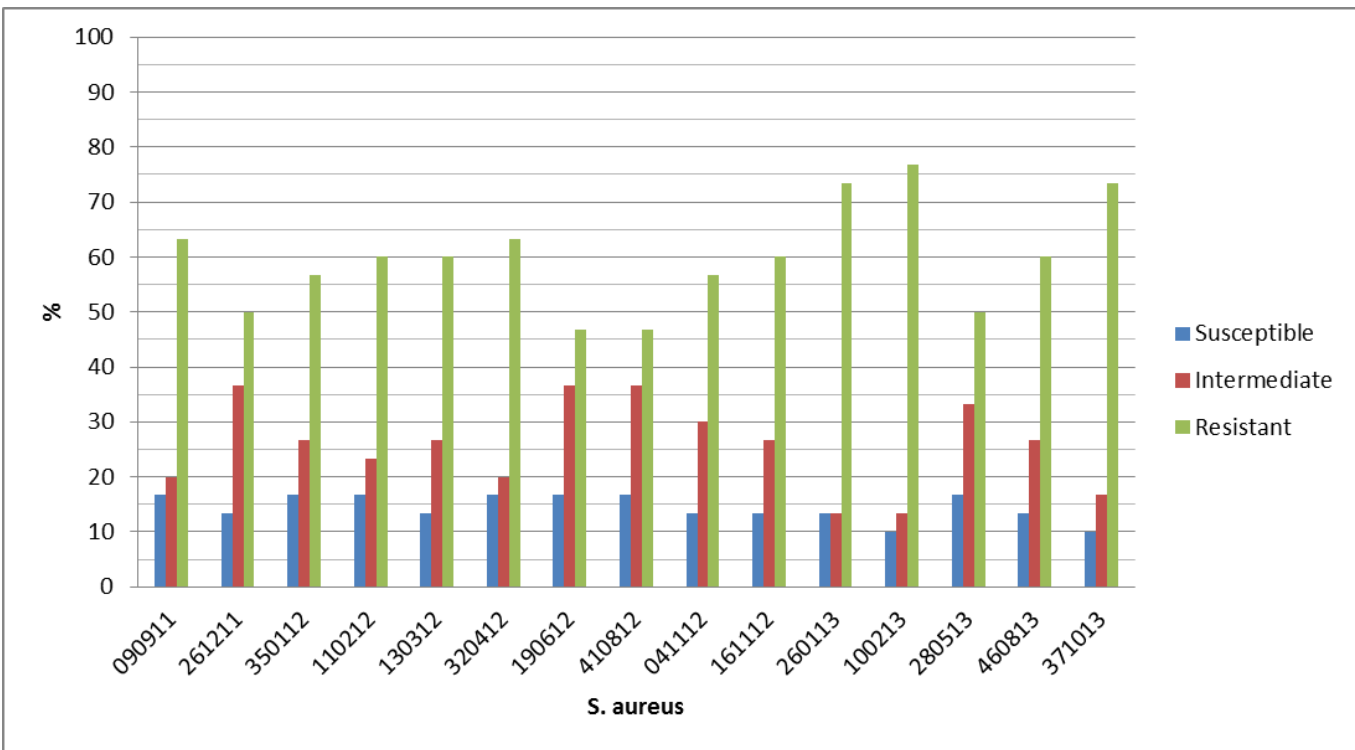

Fig. 11:- The variation in the susceptibility of the multi-drug resistant Staphylococcus aureus isolates to the tested antibiotics.

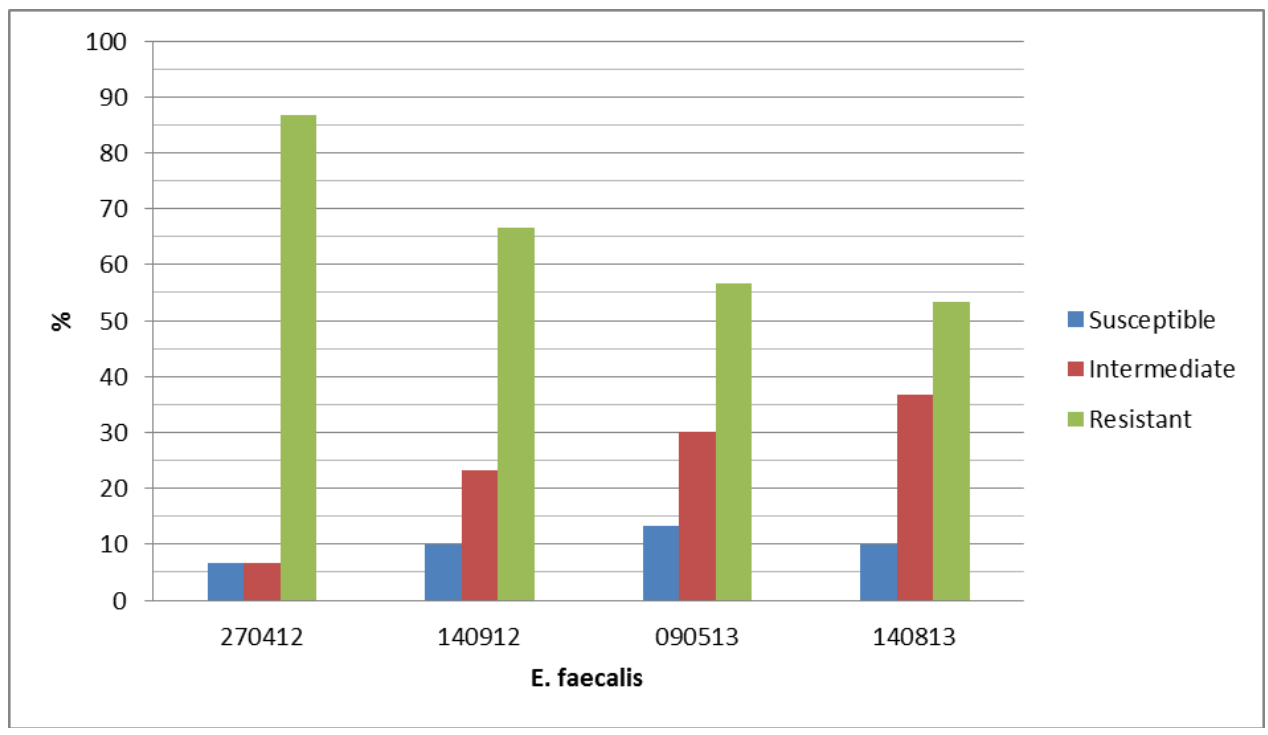

Fig. 12:- The variation in the susceptibility of the multi-drug resistant Enterococcus faecalis isolates to the tested antibiotics. 
Table(1): The antibiotic susceptibility profile for the selected bacterial isolates:

\begin{tabular}{|c|c|c|c|c|c|c|c|c|c|}
\hline \multirow[t]{3}{*}{ Isolate } & \multicolumn{9}{|c|}{ Antibiotics } \\
\hline & \multicolumn{3}{|c|}{$S$} & \multicolumn{3}{|l|}{ I } & \multicolumn{3}{|l|}{$\mathrm{R}$} \\
\hline & $\begin{array}{l}\text { Antib } \\
\text { iotic } \\
\text { code }\end{array}$ & $\mathrm{n}$ & $\%$ & Antibiotic code & $\mathrm{n}$ & $\%$ & Antibiotic code & $\mathrm{n}$ & $\%$ \\
\hline $\begin{array}{c}\text { Escherichia coli } \\
(370812)\end{array}$ & $\begin{array}{l}\text { IPM, } \\
\text { MEM }\end{array}$ & 2 & 6.7 & $\begin{array}{l}\text { AK, AMC, ATM, } \\
\text { CEP, CFP, CTX, } \\
\text { CRO, CXM, F, } \\
\text { TZP. }\end{array}$ & 10 & 33.3 & $\begin{array}{l}\text { AMP, SAM, CAZ, CIP, } \\
\text { DO, ETP, E, CN, LEV, } \\
\text { NA, NOR, OFX, PB, } \\
\text { TE, TGC, TOB, SXT. }\end{array}$ & 18 & 60.0 \\
\hline $\begin{array}{c}\text { Klebsiella } \\
\text { pneumonia } \\
(410713)\end{array}$ & $\begin{array}{l}\text { IPM, } \\
\text { MEM }\end{array}$ & 2 & 6.7 & $\begin{array}{l}\text { AK,SAM,FEP,CF } \\
\text { P,CTX,CRO,CIP, } \\
\text { CN,F,PB,TE,TGC } \\
\text { SXT. }\end{array}$ & 10 & 33.3 & $\begin{array}{l}\text { AMC,AMP,ATM,FEP,C } \\
\text { AZ,CXM,DO,ETP,E,LE } \\
\text { V,NA,NOR,OFX,PRL,T } \\
\text { OB. }\end{array}$ & 18 & 60.0 \\
\hline $\begin{array}{l}\text { Pseudomonas } \\
\text { aeruginosa } \\
(270712)\end{array}$ & $\begin{array}{l}\text { IPM, } \\
\text { PB. }\end{array}$ & 2 & 6.7 & $\begin{array}{l}\text { AK,FEP,CRO,CI } \\
\text { P,CN,MEM,F. }\end{array}$ & 7 & 23.3 & $\begin{array}{l}\text { AMC,AMP,SAM,ATM, } \\
\text { CFP,CTX,CAZ,CXM,D } \\
\text { O,ETP,E,LEV,NA,NOR, } \\
\text { OFX,PRL,TZP,TE, } \\
\text { TGC,TOB ,SXT. }\end{array}$ & 21 & 70.0 \\
\hline $\begin{array}{c}\text { Staphylococcus } \\
\text { aureus } \\
(100213)\end{array}$ & $\begin{array}{l}\text { AK, } \\
\text { IPM, } \\
\text { MEM }\end{array}$ & 3 & $\begin{array}{l}10 . \\
0\end{array}$ & CFP, NA, F,TE. & 4 & 13.3 & $\begin{array}{l}\text { AMC,AMP,SAM,ATM, } \\
\text { FEP,CTX,CAZ,CRO,CX } \\
\text { M,CIP,DO,ETP,E,CN,L } \\
\text { EV,MEM,NOR,OFX,PR } \\
\text { L,TZP,TGC,TOB,SXT. }\end{array}$ & 23 & 76.7 \\
\hline $\begin{array}{l}\text { Enterococcus } \\
\text { faecalis } \\
(100213)\end{array}$ & $\begin{array}{l}\text { Do, } \\
\text { TE. }\end{array}$ & 2 & 6.7 & PB, TOB. & 2 & 6.7 & $\begin{array}{l}\text { AK,AMC,AMP,SAM,A } \\
\text { TM,FEP,CFP,CTX,CAZ } \\
\text {,CRO,CXM, } \\
\text { CIP,ETP,E,CN,IPM } \\
\text {,LEV,MEM,NA,F,NOR, } \\
\text { OFX,PRL,TZP,TGC, } \\
\text { SXT. }\end{array}$ & 26 & 86.7 \\
\hline
\end{tabular}

More than $69 \%$ of isolates were Enterobacteriaceae; hence Escherichia coli was the most predominant pathogen isolated from urine samples (47.9\%), followed by Klebsiellapneumonia(21.5\%), Pseudomonas aeruginosa(14.9\%), Staphylococcus aureus(12.4\%) and Enterococcus faecalis(3.3\%). These results revealed that Gram-negative and Gram-positive bacteria were responsible for $84.3 \%$ and $15.7 \%$ of the MDR isolates, respectively.

In the same line of the current study, most UTIs are caused by Gram-negative bacteria which account for 80 to $85 \%$ and the leading causative organisms are Escherichia coli, Klebsiellapneumoniae(Tanviret al., 2012), and Grampositive bacteria such as Enterococcus spp. and Staphylococcus spp.(Kashefet al., 2010).

The overall isolation rate of uropathogens in this study was $65 \%$ which is like the rates reported from (Biadglegne and Abera, 2009). However, the rate was higher than other studies (Beyene and Tsegaye, 2011; Demileet al., 2012; Abdagireet al., 2014). Few data suggested variable results ranging from 9 to $34 \%$ of urine positive cultures (Jahanzebet al., 2008; Oh et al., 2013). This difference could be due to the difference in samples size, handling and sample processing techniques.

The isolation rates of Escherichia coli (48\%) and other pathogens in this study were comparable to the rates documented previously (deFrancescoet al., 2007; Beyeneet al., 2011; Demileet al., 2012; Ponnusamy and Nagappan, 2013). Various other data also documented that Escherichia coli was the predominant pathogen in UTIs patients (Tseng et al., 2008; Bahadinet al., 2011; Abdagireet al., 2014).

As studied by Manikandanet al. (2011) Staphylococcus aureuswas responsible for $20.5 \%$ of UTI cases. Similarly,Barkaet al. (2014) reported Staphylococcus to be responsible for $24.16 \%$ of the genital damage and $20.83 \%$ of urinary manifestations respectively of the total samples studied. 
Gram-negative bacteria were more responsible for UTI than Gram-positive cocci and this finding is in agreement with the findings of previous studies (Mehret al., 2004; Ayaziet al., 2010).

Significant difference was observed between genders as majority of the pathogens were isolated from females. Studies conducted all over the world have reported the differences in the prevalence rates between females and males due to physiological and anatomical differences (Theodros, 2010; ColganandWilliams, 2011; Hooton, 2012).

UTIs are considerably more common among women, nearly half of whom will experience a UTI during their lifetime (Schollum and Walker, 2012).It is estimated that 2 to $10 \%$ of pregnant woman suffer from any form of UTIs (Sharamiet al., 2007; Lee et al., 2008; Bahadiet al., 2010), which compatible with the obtained results in this study.

Pregnancy appears to increase the risk that a UTI because pregnancy can cause hormonal changes, as well as shifts in the position of the urinary tract, which make it easier for bacteria to spread to the kidneys (Hooton, 2012).

In this study, the antimicrobial susceptibility tests revealed that one hundred and twenty-one (11.6\%) isolates had multidrug resistance. Ampicillinhad the highest overall resistance of $98.3 \%$, followed by Doxycycline,Nalidixic Acid (94.2\%), Erythromycin,Piperacillin (93.4\%), Tobramycin (92.6\%), Ampicillin/Sulbactam (86.8\%), Ertapenem (84.3\%), Cefuroxime (77.7\%), Aztreonam (76.9\%), Amoxycillin/Clavulanic Acid (76\%) and Tetracycline (73.5\%).

Also, in the current study, the survey of antibiotic susceptibility revealed that Imipenem was the most effective drugs, inhibiting $89.3 \%$ of the isolated bacterial uropathogens. The other three most sensitive antibiotics exhibited susceptibility rates $71.1 \%, 57 \%, 43 \%$ were Polymyxin B,Meropenem and Amikacin, respectively.This has been observed previously in a study involving 211 clinical strains (Thibaultet al., 2004) and is of interest because Imipenem antibiotic is considered as a good alternative to ceftazidime in the treatment of disseminated disease.

Ahsanet al., (2011) reported that the highest resistance rate of Escherichia coli isolate which was obtained from urine samples was against nalidixic acid (57.7\%) followed by cotrimoxazole, ciprofloxacin, and ampicillin, respectively. However, in our study amikacin and imipenem had the widest coverage against Escherichia coli isolates (97.5\%). In another surveillance study reported that the highest resistance rate of Escherichia coli isolates which were obtained from various hospitals specimens was against tetracycline followed by amoxicillin and penicillin, respectively (Mohammadtaheriet al., 2010; Kang et al., 2011).

However, in the current study Escherichia coli, the most frequently isolated bacterium, showed high resistance rates (>80\%) to erythromycin, amoxycillin and tetracycline. Similarly, Klebsiellaspp., Proteus spp.and Pseudomonas spp. were found to be resistant to amoxycillin, erythromycin and tetracycline but sensitive to gentamicin and ciprofloxacin. Increasing drug resistance to these and other antimicrobials has been documented from previous studies (Tseng et al., 2008).

This is in concordance with the prevalence rate reported from Gupta et al.(2002) though resistance against gentamicin (50.4\%), ciprofloxacin (38.8\%) and amikacin (20.6\%) was much higher than seen in our study.

Results obtained from Ghorashiet al.(2011), suggested that Escherichia coli was extremely resistant to ampicillin but highly sensitive to amikacin in most of the hospitalized patients.

In the current study, Klebsiella pneumoniashowed resistance against commonly used antibiotics (ciprofloxacin, amoxicillin-clavulanic acid and amikacin). These findings are almost in accordance with previous studies that reported MDR K.pneumoniae(Ullahet al., 2009; Langarizadehet al., 2011; Mahdyet al., 2013; Rampureet al., 2013).

According to Ebenebeet al., (2014),Pseudomonas showed 100\% resistance to all the beta-lactam antibiotics except Imipenem. All the Gram-positive bacteria were susceptible to Imipenem.

National and regional distributions of the data areimportant to enable local prescribing practices (Laureet al., 2012). The carbapenem (imipenem) with activity against many bacteria havebeen the most active broad-spectrum antimicrobialclass documented by numerous large surveillanceprograms (Zhanelet al., 2007). 
The high levels of antimicrobial resistance inGram-negative bacteria can be attributed to antibioticmisuse in Egypt (Ashour and El-Sharif, 2009).

More likely, Atif (2006) and Jumaa (2006) reportedthat Klebsiellaspp. accounted for up to $10 \%$ of allnosocomial bacterial infections placing it among themost important infectious pathogens in hospitals over the world including Middle East; in addition toCarrëret al. (2010) and Mahdyet al. (2013) who isolated multidrug resistantK. pneumoniafrom Gizah, Egypt.

In conclusion, policies on the control of antibiotic usage have to be enforced and implemented to avoid the evolution of newer generations of pathogens with higher resistance, not only to the older generation drugs, but also to the relatively new ones. In addition, the entire microbial spectrum in various infection sites, and not just bloodstream pathogens, should be taken into account when initiating empirical antibiotic therapy.

\section{References:-}

1. Abdagire, N.V.; Chincholkar, V.V.; Kulkarni, D.M.; Nilekar, S.L. and Birajdar, S.V. (2014): Biofilm production among uropathogens and their antibiogram. Int J Pharm Bio Sci.; 5(1): 261-266.

2. Ahsan, B., Beiranvand, S., Abdulmaleki, N., Mohamadi, H. and Kalantar, E. (2011): A surveillance study of antimicrobial susceptibility in 11 hospitals in Kurdistan Province, African Journal ofMicrobiology Research. 5 (20): 3157-3161.

3. Ashour H A and El-Sharif A. (2009): Species distribution and antimicrobial susceptibility of gram-negative aerobic bacteria in hospitalized cancer patients. Journal of Translational Medicine; 7:14.

4. Atif A. (2006): Frequency and antimicrobial susceptibility patterns of bacterial pathogens isolated from septicemic patients in Makkah hospitals, Saudi Medical Journal; 27:361-367.

5. Atlas, R.M. (2010). Handbook of Microbiolgical Media, Fourth Edition, London.CRCPress.P. 1226.

6. Ayazi P, Mahyar A, Jahani HH, and Khabiri S (2010).Urinary Tract Infections in Children. Iran. J. Pediatr. Soc. 2(1):9-14.

7. Bahadi, A., El Kabbaj, D., Elfazazi, H., Abbi, R., Hafidi, M.R., Hassani, M.M., Moussaoui, R., Elouennass, M., Dehayni, M. and Oualim, Z. (2010) Urinary tract infection in pregnancy. Saudi J Kidney Dis Transpl, 21, 342344.

8. Bahadin J, Teo SSH, and Mathew S. (2011): Aetiology of community-acquired urinary tract infection and antimicrobial susceptibility patterns of uropathogens isolated. Singapore Med J; 52: 415-420.

9. Barka, M. S., Benyoub, N. and Zaoui, H. (2014): Prevalence of urogenital tract infections during pregnancy in Maghnia hospital (Algeria). Int. J. Curr. Microbiol. App. Sci 3(1): 1-7.

10. Beyene, G. and Tsegaye, W. (2011): Bacterial uropathogens in urinary tract infection and antibiotic susceptibility pattern in Jimma University Hospital, Ethiopia. Ethiop J Health Sci 2011; 21: 141-146.

11. BiadglegneF, and Abera B. (2009): Antimicrobial resistance patterns of bacterial isolates from urinary tract infections at FelegeHiwot Hospital, Ethiopia. Ethiop J Health Dev; 23: 236-238.

12. Carrër A, Poirel L, Yilmaz M, Akan O, Feriha C, Cuzon G, Matar G, Honderlick P and Nordmann P. (2010): Spread of OXA-48-Encoding Plasmid in Turkey and Beyond. Antimicrobial Agents and Chemotherapy; 54: 1369-1373.

13. Chessbrough M. (2000). District Laboratory Practice in Tropical Countries, Part 2.Cambridge University Press, Cambridge, UK.pp 157-158, 188.

14. Clinical and Laboratory Standards Institute (CLSI) (2012).Performance Standards for Antimicrobial Disk Susceptibility Tests. CLSI document M100-S17 (ISBN 1-56238-625-5). Pennsylvania, USA.

15. Colgan R, Williams M. (2011): Diagnosis and treatment of acute uncomplicated cystitis. American family physician.84(7):771-776.

16. de Francesco MA, Giusepe R, Laura P, Riccardo N, and Nino M. (2007): Urinary tract infections in Brescia, Italy: Etiology of uropathogens and antimicrobial resistance of common uropathogens. Med SciMonit; 13: 136144.

17. Demile T, Beyene G, Melaku S, and Tsegaye W. (2012): Urinary bacterial profile and antibiotic susceptibility pattern among pregnant women in North West Ethiopia. Ethiop J Health Sci. 22: 121-128.

18. Ebenebe, J. C., Emeka-Okafor, K. M. Akujo, C. N., Ezeanya, C. C. Agbakoba, N. R. and Egwuatu, C. C. (2014): Plasmid Profile of Uropathogens among Children British Journal of Medicine \& Medical Research. 4(5): 11951203. 
19. Ghorashi Z, Ghorashi S, Soltani-Ahari H, and Nezami N. (2011): Demographic features and antibiotic resistance among children hospitalized for urinary tract infection in northwest Iran. Infect Drug Resist. 4: 171176.

20. Gupta K, Hooton TM, and Miller L. (2011): Managing uncomplicated urinary tract infection making sense out of resistance data. Clinical Infectious Diseases. 53(10):1041-1042.

21. Gupta V, Yadav A, and Joshi RM. (2002): Antibiotic resistance pattern in uropathogen. Indian J Med Microbiol; 20: 96-8.

22. Hamill, T.M., et al. (2007): Strategies for the development of the urinary catheter. Expert Review of Medical Devices. 4(2): 215-225.

23. Hensyl, W.R. (1994).Bergey's manual of Determinative Bacteriology $9^{\text {th }}$ ed.William and Wilkins, Baltimore.

24. Holt, J.G., Krieg, N.R., Sneath, P.H., Staley, J.T., and Williams, S.T. (1996).Bergey’s Manual ${ }^{\circledR}$ of Determinative Bacteriology. $10^{\text {th }}$ ed. Williams \& Wilkins, Baltimore, MD.

25. Hooton TM. (2012): Clinical practice. Uncomplicated urinary tract infection. The New England journal of medicine. 366(11):1028-1037.

26. Jahanzeb M, Siddiqui T, and Idris M (2008).Frequency and clinical presentation of UTI among children of Hazara Division, Pakistan. J. Ayub Med. Coll. Abbottabad, 20: 63.

27. Jain, A. Awasthi, A. and Kumar, M. (2007): Etiological and antimicrobial susceptibility profile of nosocomial blood stream infections in neonatal intensive care unit. Indian Journal ofMedical Microbiology, 25(3): 299300 .

28. Jonaidi, J. N, Ranjbar R, Haghi-Ashtiani MT, Abedini M, and Izadi M (2009). The study of prevalence and antimicrobial susceptibility of tracheal bacterial strains isolated from pediatric patients. Pak J BiolSci, 12: 4558.

29. Jumaa P. (2006): Frequency of isolation of pathogens from nosocomial bloodstream infection in a tertiary referral hospital in the UAE. International Jorunal of Infectious Diseases; 218.

30. Kalantar E, Motlagh M, Lornejad H, and Reshadmanesh N. (2008): Prevalence of urinary tract pathogens and antimicrobial susceptibility patterns in children at hospitals in Iran. Iranian Journal of Clinical Infectious Diseases. 3(3):149-153

31. Kang, C. I. Chung, D. R. Son, J. S. Ko, K. S. Peck, K. R. and Song, J. H. (2011): Clinical significance of nosocomial acquisition in urinary tract-related bacteremia caused by gram-negative bacilli," American Journal of Infection Control, 39(2): 135-140, 2011.

32. Kashef N, Djavid GE, and Shahbazi S. (2010): Antimicrobial susceptibility patterns of community-acquired uropathogens in Tehran, Iran. J Infect DevCtries; 4: 202-206.

33. Langarizadeh N, Ahangarzadeh RM, Aghazadeh M, and Hasani A (2011). Prevalence of multi-drug resistant (MDR) Klebsiella pneumonia among children and adults with urinary tract infection referred to tabriz teaching hospitals. Quarterly J. Biol. Sci. 4:9-17.

34. Laure M, Kempf M, Cavallo J, Chomarat M, Dubreuil L, Maugein J, Muller-Serieys C and Roussel-Delvallez M. (2012): Comparative in vitro activity of Meropenem, Imipenem and Piperacillin/tazobactam against 1071 clinical isolates using 2 different methods: a French multicentre study. BMC Infectious Diseases; 10:72.

35. Lee, M., Bozzo, P., Einarson, A. and Koren, G. (2008): Urinary tract infections in pregnancy. Can Fam Physician, 54, 853-854.

36. Mahdy, H.M., Sharaf, A.M., Al-Aaser, M.M. and El-Sayed, H.M. (2012): Diffusion method and Vitek machine analysis of ESBLs for Klebsiellapneumoniaea comparable study.Researcher; 4(12):50-56.

37. Mahdy, H.M., Sharaf, A.M., Al-Aaser, M.M. and El-Sayed, H.M. (2013): Mechanism of ESBL Production of Klebsiellapneumoniaeisolated from Egypt. N Y Sci J; 6(1):1-8.

38. Manikandan, S., Ganesapandian, S., Singh, M. and Kumarguru A. K. (2011). Emerging of Multi drug Resistance Human Pathogens form Urinary Tract Infections. Curr Res Bacteriol. 4(1):9-15.

39. McLoughlin TG Jr,andMatar MJ. (2003): Antibiotic resistance patterns of uropathogens in pediatric emergency department patients. Emerg Med. 10(4): 347-351.

40. Mehr S, Powell C, and Curtis N (2004).Cephalosporin resistant urinary tract infections in young children. J. Paediatr Child Health 40:48-52.

41. Mohammadtaheri, Z. Pourpaki, M. Mohammadi, F. Namdar, R. and Masjedi, M. R. (2010): Surveillance of antimicrobial susceptibility among bacterial isolates from Intensive Care Unit Patients of a Tertiary-Care University Hospital in Iran: 2006-2009, Chemotherapy, 566, pp. 478-484.

42. Oh E, Lee H, Lim HS, and Park Y (2013). Epidemiology and Resistance Patterns of Bacterial Pathogens in Urinary Tract Infections in the Northern Gyeonggi-do Area during 2007-2011. Lab. Med. Online 3:34-39. 
43. Ponnusamy P and Nagappan R. (2013): Extended Spectrum Beta-lactamase, Biofilm-producing Uropathogenic Pathogen and Their Antibiotic Susceptibility Patterns from Urinary Tract Infection. International Journal of Microbiological Research. 4(2): 101-118.

44. Rampure R, Gangane R, Oli AK (2013). Prevalence of MDR-ESBL producing Klebsiellapneumoniae isolated from clinical Samples. J. Microbiol. Biotech. Res. 3(1):32-39.

45. Sanchez GV, Master RN, Karlowsky JA, and Bordon JM. (2012): In vitro antimicrobial resistance of urinary Escherichia coli isolates among U.S. outpatients from 2000 to 2010. Antimicrobial Agents and Chemotherapy. 2012:2181-2183.

46. Schollum JB, and Walker RJ. (2012): Adult urinary tract infection. British journal of hospital medicine. 73(4): 218-223.

47. Sharami SH, Afrakhteh M, and Shakiba M. (2007): Urinary tract infections in pregnant women with bacterial vaginosis. J ObstetGynaecol. 27: 252-254.

48. Simerville JA, Maxted WC, Pahira JJ. (2005). "Urinalysis: a comprehensive review". American Family Physician. 71 (6): 1153-62.

49. Tanvir R, Hafeez R, and Hussain S (2012).Prevelance of Multi Drug Resistant E. coli in patients of UTI Registring at a Diagnostic Laboratory in Lahore, Pakistan. Pak. J. Zool. 44:707-712.

50. Theodros G. (2010): Bacterial pathogens implicated in causing urinary tract infection (UTI) and their antimicrobial susceptibility pattern in Ethiopia. Revista CENIC. CienciasBiológicas; 41: 1-6.

51. Thibault F M, Hernandez E, Vidal D R, Girardet M. and Cavallo J D. (2004): Antibiotic susceptibility of 65 isolates of BurkholderiapseudomalleiandBurkholderia mallei to 35 antimicrobial agents. Journal of Antimicrobial and Chemotherapy; 54: 1134-1138.

52. Tseng MH, Lo WT, Lin WJ, Teng CS, Chu ML, and Wang CC. (2008): Changingrend in antimicrobial resistance of pediatric uropathogens in Taiwa. PediatrInt; 50: 797-800.

53. Ullah F, Malik SA, and Ahmed J (2009).Antimicrobial susceptibility pattern and ESBL prevalence in Klebsiellapneumoniae from urinary tract infections in the North-West of Pakistan. Afr. J. Microbiol. Res 3:676680.

54. Yilmaz, N., N. Agus, S. G. Yurtsever, H. Pullukcu, Z. Gulay, A. Coskuner, S. Kose, S. Aydemir, N. Gulenc and Ozgenc, O. (2009): Prevalence and antimicrobial susceptibility of Escherichia coli in outpatient urinary isolates in Izmir, Turkey. Med SciMonit 15(11):161-165.

55. Zhanel G G, Dilay W R, Thomson K, Rubinstein E, Hoban J D, Noreddin A M and Karlowsky J A. (2007): Comparative review of the carbapenems. Drugs; 67: 1027-1052. 